\title{
LOS NEGROS NO CUENTAN. ACERCA DE LAS DEMANDAS DE RECONOCIMIENTO DE LOS AFRODESCENDIENTES EN CHILE Y LA EXCLUSIÓN PIGMENTOCRÁTICA.
}

\section{Black People don't Count. About the Demands for Recognition of Afro-descendants in Chile and the Pigmentocratic Exclusion.}

\section{LUIS EUGENIO CAMPOS*}

Fecha de recepción: 16 de agosto de 2017 - Fecha de aprobación: 30 de octubre de 2017

\begin{abstract}
Resumen
La población afro en Chile lleva años demandando reconocimiento sin mayores éxitos. Esto se ha reflejado en la falta de una normativa específica que ampare a los afrodescendientes, como también en la negación a incluir una pregunta de caracterización afro en los censos nacionales de población. Las razones de esta exclusión comienzan muchos años atrás y tienen que ver con la negación de una identidad racial y cultural por razones pigmentocráticas, de marcado carácter nacionalista, con trasfondos racistas, que habiéndose establecido desde tiempos coloniales, se prolongan desde la Guerra del Pacífico hasta nuestros días. La hipótesis que levanto plantea que la negación, la invisibilización, la exclusión y la falta de reconocimiento de los afrodescendientes son producto de antiguas formas de pigmentocracia nacionalista en las cuales la pertenencia a la nación está dada por la exclusión de aquellos pigmentos más oscuros, no solo siendo cuestionado el ascenso social de indígenas y afrodescendientes, sino también, en el caso de los negros, la misma posibilidad de ser considerados chilenos.
\end{abstract}

Palabras clave: Afrodescendientes, pigmentocracia, políticas públicas, reconocimiento.

\begin{abstract}
The Afro population in Chile has been demanding recognition for years without great success. This has been reflected in the lack of specific legislation to protect Afro-descendants, as well as in the refusal to include an Afro characterization question in national population censuses. The reasons for this exclusion begin many years ago and concern the denial of a racial and cultural identity for pigmentocratic reasons, with a marked nationalist character, with racist understones, which, having been established since colonial times, continues from the Pacific War to our days. The hypothesis that I raise is that the negation, the invisibility, the exclusion and the lack of recognition of afrodescendents are the product of old forms of nationalist pigmentocracy in which the national belonging is given by the exclusion of those of darker skin pigmentation, not only questioning the social ascension of indigenous and afrodescendent people, but also, in the case of black people, the possibility of being considered Chileans.
\end{abstract}

Keywords: Afro-descendants, pigmentocracy, public policies, recognition.

\footnotetext{
* Dr. en Antropología. Profesor Investigador de la Universidad Academia de Humanismo Cristiano (UAHC) y del Centro de Estudios Interculturales e Indígenas (CIIR), Santiago, Chile. El artículo está enmarcado en el Proyecto Fondecyt 1150876, Proyecto Fondap CIIR Proyecto Recoleción y Clasificación de Datos etnoterritoriales afrodescendientes de la Región de Arica y Pariancota. Correo-e: Icampos@academia.cl, luiseugeniocampos@gmail.com
} 


\section{Presentación}

En Chile, en el Censo Abreviado de 2017, no hubo una pregunta sobre población afrodescendiente. A pesar que las organizaciones afro de Arica han pedido su incorporación al Censo desde el año 2008 y también han presentado una moción de reconocimiento al parlamento, después de 10 años siguen sin ser contados y sin ser reconocidos. En este artículo reflexiono acerca de la cronología de hechos que se han dado en los últimos años y sobre las implicancias y trasfondos de esta evidente negación. Para entender esta situación se debe partir considerando la imagen de país blanco mestizo que Chile ha mostrado a lo largo de su historia (Waldman, 2004), como también la construcción de un discurso nacionalista (Cid, 2012), que ha propiciado que en Chile se avance con un sistema de negación y de exclusión que ha afectado históricamente a los pueblos indígenas y hoy también a los afrodescendientes. Abordo los argumentos que se han usado para reafirmar las demandas de reconocimiento por parte de las organizaciones y otros actores vinculados al movimiento, como también de aquellos que han negado a la población afrodescendiente, especialmente autoridades encargadas de dar oído a sus demandas. Por último, reseño las ambigüedades presentes en las políticas públicas de un Estado que al igual que en materias indígenas, tiene una posición ambivalente y algunas veces contradictoria, negando por un lado las demandas, pero en otros casos aceptando y apoyando el reconocimiento.

\section{Metodología y encuadramiento teórico}

Este artículo se sustenta en los resultados de investigaciones que se vienen desarrollando desde fines del 2013 en un trabajo colaborativo con las organizaciones afrodescendientes. En conjunto con ellos y con el apoyo de la Municipalidad de Arica, se llevó a cabo el Proyecto Recolección y clasificación de datos etnoterritoriales afrodescendientes de la Región de Arica y Parinacota, cuyo objetivo fue "recolectar, clasificar, sistematizar e informar sobre las características culturales distintivas que tienen hoy los afrodescendientes de la región" (Campos \& Espinosa, 2017, p.6). Este estudio apuntaba a la generación de datos relevantes que permitieran enmarcar las políticas públicas con afrodescendientes, "como así mismo, apoyar los procesos legales en torno al reconocimiento de los afrodescendientes como un pueblo distintivo, con sus respectivos derechos culturales asociados" (Campos \& Espinosa, 2017, p.6).

Se trabajó principalmente con etnografía, levantamientos históricos, construcción de genealogías, análisis de actividades productivas, caracterización de actividades ceremoniales y entrevistas a líderes del movimiento, como también a líderes de opinión en la ciudad de Arica. Durante todo el estudio se mantuvo una perspectiva intercultural, de género y de diferencia de ocupación territorial, de manera tal de considerar la mayor diversidad en el proceso de caracterización de lo afrodescendiente, incluyendo tanto a las personas que se identifican como afro, como a otros actores relevantes indígenas y mestizos de la ciudad de Arica y de sus valles. También se mantuvo una perspectiva colaborativa y de participación en diferentes eventos públicos en donde se está trabajando la cuestión afrodescendiente en el país, 
como asimismo la participación en talleres de formación de competencias interculturales para funcionarios públicos orientados a sensibilizar sobre la cuestión afro en Chile.

Teóricamente abordo la cuestión afrodescendiente como un movimiento étnico, más cercano a lo que Eduardo Restrepo (2013) ha llamado los procesos de etnización de la negridad, en donde se expresa un movimiento negro con características culturales y étnicas, perspectiva cercana a la que utilicé con anterioridad para caracterizar a los afrodescendientes en México (Campos, 1999). Para trabajar con la cuestión racial y el racismo me baso en los estudios de construcción social de la racialidad (Briones, 1998) y la reproducción del racismo vinculado a las elites (Van Dijk, 2003). Sostengo, siguiendo a Wade $(2000,2005)$, que tanto indígenas como afrodescendientes han sufrido procesos de marcación con categorías estigmatizantes y también procesos de invisibilización y negación de sus identidades (Oliveira, 1998, 2002). Estos procesos han ocurrido tanto a nivel discursivo (discursos sobre la blancura de la nación), como también se han dado a partir de políticas racistas y excluyentes de discriminación y persecución de los indígenas y de los afrodescendientes, como la Campaña de Pacificación de la Araucanía, o la campaña de Chilenización de la Pampa (González, 2004). Como plantea Wade (2000) analizando la cuestión racial y la etnicidad en América Latina:

El tipo de mezcla al que se hacía referencia a menudo estaba sesgada hacia lo blanco: la inmigración europea se estimulaba con frecuencia, y hasta tenía el auspicio estatal; y más en general, el proceso de la mezcla se podía considerar como un blanqueamiento progresivo de la población. Supuestamente, se esperaba que la mezcla produzca la eliminación de los negros y de los indígenas y la creación de una sociedad mezclada cercana al extremo más distintivamente blanco del espectro. (p.42)
A partir de estas políticas se levantan sociedades nacionales en donde la posición social, el estatus socioeconómico, está marcado por lo que Alejandro Lipschutz (1944) ha caracterizado como pigmentocracia o también como la ley del espectro de los colores raciales, donde
...el pigmento, más que cualquier otro carácter físico, sirve de símbolo para el grupo social combatiente; este necesita siempre sus 'colores' -y la naturaleza los ofrece a veces bondadosamente, y con esto mismo parece justificar las pretensiones sociales del grupo. (p.72)

Para Lipschutz (1963), es el "punto de partida de los privilegios sociales de los cuales goza el señor blanco. En defensa de sus privilegios sociales el blanco invoca la ley del espectro de colores raciales como ley natural e implacable" (p. 260). Así, el color, las diferencias físicas como la pigmentación diferencial de la piel, permiten distinguir a los ciudadanos, generando privilegios para aquellos que son racial y culturalmente más blancos. Incluso más, Lipschutz plantea que como mecanismo de defensa aparecerá lo que denomina Hiprocresía Racial, ya que: "Al cambiar las condiciones económicas dominantes, se pondrá en acción la Hipocresía Racial, invocando diferencias raciales inexistentes, con el fin de permitir la sobrevivencia de la Ley del Espectro" (Lipschutz, 1944, p. 84). La idea de la pigmentocracia ha sido desarrollada en tiempos actuales por Edward Telles caracterizando a las sociedades latinoamericanas como pigmentocracias, ya que en ellas el color de la piel es central para la comprensión de la estratificación social (Telles, 2014). En la síntesis de una de sus trabajos dedicados a la educación Telles (2012) concluye categóricamente: 
En resumen, se muestra que la mayor parte de los países de América Latina y el Caribe puede ser caracterizada con seguridad como pigmentocracias. Las personas más educadas tienden a tener el color de la piel más claro, mientras que aquellos con menor nivel educativo tienden a tenerlo más oscuro. (p.7)

Enfrentando estos procesos de marcación, discriminación y de exclusión, se han levantado en los últimos años demandas de reconocimiento, primero de indígenas como parte de la llamada emergencia indígena de América Latina (Bengoa, 2000) y luego la demanda de reconocimiento afro de principios del S. XXI. Lo anterior ha tenido como trasfondo el fortalecimiento de un movimiento internacional pan indígena y afrodescendiente (Guzmán \& Geler, 2013; Geler, 2010; Walker, 2012) y la consolidación de los procesos de democratización en América Latina de fines de 1980, los que abrieron la puerta para nuevas demandas de reconocimiento y generaron cambios en los distintos países que permitieron abordar la diferencia, tanto racial como culturalmente expresada (Campos, 2016). Estos cambios fueron un campo propicio para la revalorización de antiguas formas identitarias y el surgimiento de procesos etnogenéticos que se han dado tanto en pueblos indígenas como en afrodescendientes (Campos, 2014; Duconge \& Guizardi, 2014b). Por último, los procesos migratorios se han acentuado en los últimos años en Chile y han provocado que una gran cantidad de afrodescendientes provenientes de países como República Dominicana, Haití y Colombia, hayan llegado al país (Valle, 2014), lo que está obligando en la actualidad a tener nuevas formas de comprensión de la diversidad racial y cultural en Chile. De ahí que lo que se discute en este artículo tome relevancia ya que al parecer las bases culturales de la sociedad chilena y su persistente racismo, serán un escollo difícil de superar a la hora del reconocimiento de lo negro como componente de la nación.

\section{Los afrodescendientes en Arica}

La población afrodescendiente de Arica se remonta a tiempos coloniales y a la trata transatlántica europea que desplazó a poblaciones africanas hasta el Virreinato del Perú (Thomas, 1998; Klein, 1999; Gilroy, 2014). Arica tuvo en esos tiempos una doble importancia, tanto como productora agropecuaria y también como puerto de embarque del mineral del Potosí (Duconge \& Guizardi, 2014a). Los negros fueron asentándose tanto en los valles circundantes, sobre todo Azapa y también en la misma ciudad de Arica, la cual a lo largo de su historia fue mayoritariamente afrodescendiente (Briones, 2004; Campos \& Espinosa, 2017). A mediados del S. XIX luego del aumento de la explotación del salitre, comenzarán a llegar nuevos contingentes poblacionales, sobre todo migrantes europeos, si bien la ciudad continuó siendo en su mayoría afro, lo que queda en evidencia con los censos que se realizaron en la región cuando todavía estaba bajo soberanía peruana (Díaz, Galdames \& Ruz, 2013). Luego de la Guerra del Pacífico y de las campañas de chilenización, los negros pasaron a representar la peruanidad que se quería erradicar de la región lo que implicó persecuciones, exilio y discriminación, instalándose desde ese entonces la idea de que los negros no eran chilenos (González, 2004; Díaz, Galdames \& Ruz, 2013). Sus casas fueron marcadas con cruces y la mayor parte de las familias debieron partir al exilio. Solo unos pocos consiguieron regresar y la mayoría perdió tierras y propiedades que algunos reclaman hasta el día de hoy. Las fami- 
lias fueron divididas, encontrándose parientes de los actuales afrochilenos en diversas localidades en el Perú, algunas cercanas como Sama y Tacna y otras más lejanas como Arequipa y Lima (Alarcón, Araya \& Chávez, 2017). Comienza entonces el ocultamiento de los negros quienes asumen una serie de estrategias que les permitieran seguir en el territorio, entre ellas, matrimonio intencionado con personas no afrodescendientes, abandono de las condiciones de ruralidad y procesos de blanqueamiento que incluían pérdida de los lazos familiares y rituales (Campos \& Espinosa, 2017). A principios del S. XX la región recibirá el influjo de ex-trabajadores de las salitreras quienes llegarán a vivir a la ciudad producto del fin de dicha actividad extractivista. Ya en 1950 el estado chileno asumirá con mayor fuerza el desarrollo nacional de la frontera norte con la creación de la Junta de Adelanto y la llegada de nuevos chilenos provenientes del sur, muchos de ellos profesionales, los cuales van a conformar la región hasta la actualidad (Ruz, Galdames \& Díaz, 2015). Desde entonces y a lo largo de 100 años, la presencia afrodescendiente será invisibilizada y sujeta al régimen de crisol de las razas y de un mestizaje que evita parecer racista a partir del discurso de la disolución de las diferencias y de la creación de un nuevo sujeto, el mestizo ariqueño, quién será heredero de múltiples tradiciones culturales, entre ellas la afrodescendiente, la indígena y la española, además de otras procedencias europeas, predominando un marcado carácter nacionalista.

Durante la segunda mitad del S. XX se mantendrá esta situación de invisibilización, lo que no implicó necesariamente que se haya diluido completamente la presencia negra. Según datos de nuestra investigación, no hubo década en más de 400 años de historia colonial y republicana en que no apareciera algún vestigio de los negros de Arica (Briones, 2004). A modo de ejemplo, en 1619 se señala el nombramiento temporal de dos alcaldes negros para la ciudad (Wormald, 1969); en 1681 negros y mulatos aparecen defendiendo el puerto de Arica del ataque de piratas (Wormald, 1972); en 1750 se establece el criadero de negros en el Valle de Lluta (Wormald, 1969); a partir de 1854 se señalan conflictos derivados de la abolición de la esclavitud en el Perú, firmada el día 3 de diciembre de ese año por el Presidente Ramón Castilla (Díaz, Galdames \& Ruz, 2013). Entre 1881 y 1929 comienza la chilenización de la región luego de la Guerra del Pacífico, lo que implicó una focalizada persecución hacia los negros los que eran identificados como ejemplo de lo peruano (González, 2004). En la propaganda nacionalista se multiplicaron los afiches en donde el peruano "traidor" era representado por un afrodescendiente (Díaz, Galdames \& Ruz, 2013). Entre 1925 y 1945 los negros de Arica y Azapa resisten a la epidemia de malaria que afecta a la región, lo que fue documentado a partir de las investigaciones del Dr. Juan Noe quién pesquisa la resistencia de los negros a dicha enfermedad (Wormald, 1972). En 1957 Luis Urzúa (1964), un intelectual local, constata que:

Hasta el día de hoy subsisten, algo desteñidos, en el Valle de Azapa, donde fueron ocupados en las plantaciones de caña de azúcar y molinos de aceite. Su inmunidad a las enfermedades tropicales favoreció su desarrollo y lograron formar un grupo étnico considerable, a punto que Arica semejaba un poco a África, no sólo en la fonética sino en el colorido, hasta principios de este siglo. Las características morenas se delatan todavía en muchos vecinos de calidad social distinguida. (p. 46) 
Por último, se debe reseñar que en las décadas posteriores no hubo año en el cual un descendiente de africano no figurara en alguna actividad, ya sea en deportes, elegidos como alcaldes y diputados, o bailando en la principal fiesta que la ciudad tenía en ese entonces, la llamada Ginga (Campos \& Espinosa, 2017). Y todo esto antes del año 2000 en que comienza la actual visibilidad de la población afrodescendiente de Arica cuando son invitados a la Conferencia Pre-Durban en Santiago donde por primera vez se hacen notar públicamente como negros (Salgado, 2013; Báez, 2010). Luego de la participación de líderes afroariqueños en Durban se comienzan a crear las primeras organizaciones, las que se han multiplicado y han pasado a ser un actor relevante de la vida cotidiana de la región, sobre todo con sus bailes, culinaria y otras expresiones artísticas y productivas que han sido retomadas y orientadas hacia la visibilización de lo afro en Arica y también en el resto del país (Del Canto, 2003; Espinosa, 2013). Producto de lo anterior, en el año 2007, comienzan las gestiones para ser incorporados en el Censo 2012, como también para la promulgación de una ley específica que reconozca a los afrodescendientes de Arica. $Y$ si bien ninguna de las dos demandas se ha conseguido lograr, la presión del movimiento social ha tenido impactos sobre todo en el ámbito del gobierno regional, el que ha desarrollado políticas públicas pertinentes que van desde un estudio específico de población afrodescendiente (ENCAFRO), la instalación de una Oficina Afrodescendiente en el Municipio de Arica, la creación de una Ruta del Esclavo, convocatoria a un comité de allegados para apoyar demandas habitacionales en el Valle de Azapa y fomento de la música y los bailes a partir de iniciativas concursables desde el Consejo Nacional de la Cultura (CNCA) y de la inclusión de los afro- descendientes en los carnavales de la ciudad, antes mayoritariamente de raigambre indígena o relacionados con los bailes religiosos que se practican en la celebración de divinidades católicas (Campos \& Espinosa, 2017).

Amparados en un movimiento que tiene 17 años, los afrodescendientes se han enfrentado a un discurso que desde el inicio los ha negado como componente de la chilenidad. Las razones de esta exclusión son las que pasaré a trabajar a continuación a partir de una caracterización tanto de las demandas realizadas, como de las respuestas que se han tenido principalmente desde el aparato público, pero también desde otros sectores de la sociedad civil, tanto a nivel regional como nacional. La hipótesis que levanto plantea que la negación, la invisibilización, la exclusión y la falta de reconocimiento de los afrodescendientes son producto de antiguas formas de pigmentocracia nacionalista en las cuales la pertenencia a la nación está dada por la exclusión de aquellos pigmentos más oscuros, no solo siendo cuestionado el ascenso social de indígenas y afrodescendientes, sino también, en el caso de los negros, la misma posibilidad de ser considerados chilenos.

\section{Cronología de una negación de la diferencia.}

En el año 2008 se presentó en el parlamento la primera moción de reconocimiento de los afros en Chile. En paralelo se realizaron las conversaciones con el Instituto Nacional de Estadísticas (INE) conducentes a que en el Censo de 2012 se incorporara la variable afrodescendiente. Según la dirigente afro Marta Salgado (2013), luego del Censo 2002, surgió la inquietud de los afros por ser contados en el siguiente censo. Ya en esa fecha Chile era uno de los pocos países 
en América Latina que no tenía pregunta diferenciadora, siendo hoy, junto con República Dominicana, los únicos que no han incorporado ese tipo de consulta en el Censo (Cepal $\left.{ }^{1}, 2013\right)$.

Esta situación no era extraña para el país, ya que recién en 1992 Chile incorporó una pregunta de identificación indígena, lo que si bien se volvió a dar en el 2002, se hizo cambiando la pregunta, lo que no ha permitido comparar los resultados. En el 2012 se construyó una tercera formulación, y aunque fueron publicados los resultados preliminares, el Censo no fue validado por errores garrafales en la metodología que se utilizó para la recolección de la información. Interesa destacar cómo, en el caso indígena, siguen operando mecanismos de invisibilización y marcación (Briones, 2002) teniendo que transcurrir muchos años para ser plenamente reconocidos, estando todavía pendiente el reconocimiento constitucional. Si seguimos los planteamientos de Wade (2000), la semejanza en la manera en que los estados-naciones enfrentan las demandas de indígenas y afrodescendientes, reflejan mecanismos de exclusión que obedecen a una misma matriz eurocéntrica y pigmentocrática (Lipschutz, 1944).

Por lo anterior no es de extrañar lo que estaba sucediendo con los afrodescendientes en 2008, cuya demanda se enfrentó a una estructura administrativa llena de prejuicios y de desinterés por contar ese tipo de diferencia. Al parecer, en Chile los negros no cuentan ya que existen impedimentos culturales que hacen considerar a esa población. En este contexto, en el 2008 las conversaciones comenzaron con la incredulidad de la contraparte y luego de muchas conversaciones y de la rotunda negativa a avanzar sobre el tema, las organizaciones afro se reunieron y comenzaron a presionar de una manera distinta (Salgado, 2013). Si bien en la ciudad de Arica desde el año 2003 se habían hecho visibles cada 6 de enero cuando comenzaron a celebrar la Pascua de Negros y sus tambores ya sonaban como emblema identitario, nunca habían sido utilizados de manera tan directa en la protesta social. Así, durante el 2009 se repitieron incesantemente las batucadas frente a la sede de los servicios públicos de la región de Arica, hasta que por fin la autoridad se sensibilizó. El cuestionamiento a la existencia de los afro había quedado por el suelo, ya que los no existentes no solo estaban por la ciudad en sus días de fiestas, con sus carnavales y tumbes, sino que también interrumpían el trabajo de los servicios públicos y no dejaban tranquilos a nadie. Los negros realmente existían y estaba exigiendo ser contados en el censo e incorporados en las políticas públicas (Espinosa, 2013).

A partir de ese momento se reiniciaron las conversaciones que partieron de las siguientes afirmaciones: los negros existen, están en Arica, no se tiene la experiencia para desarrollar la pregunta, no hay tiempo para incorporarlos en el censo 2012. Asumiendo esas constataciones, tanto el INE, el Gobierno Regional y la Municipalidad de Arica, enfrentaron las demandas de las organizaciones y propusieron trabajar por un estudio específico de población que se realizara en la Región de Arica y Parinacota y que permitiera ayudar a generar la experiencia para poder contar a los afrodescendientes, como también tener una primera aproximación a las características culturales y sociales de esta población. Así, desde el 2011 se comenzó a trabajar en la ENCAFRO, Encuesta de Caracterización Afrodescendiente, cuyos resultados se entregaron en el año 2014 y dieron una cifra que representaba el $4,7 \%$ de la región, un total 
de 8.415 personas (INE, 2014). Considerando que la metodología utilizada fue en parte censo y en parte muestral, se estima que este número podría variar significativamente, sobre todo pensando en lo que ha avanzado el proceso de autoreconocimiento en los últimos años y por el incremento de los procesos migratorios.

Con respecto a los resultados, estos fueron presentados en abril de 2014 y en su lanzamiento participó la recién asumida directora del INE. En esa fecha, ya eran conocidos los graves problemas en la recolección de información que tuvo el Censo 2012, lo que obligaría a repetirlo en 2017. Por lo mismo, y ante la valoración que estaban dando todos los actores al informe, se le planteó a la Directora Nacional, la necesidad de que el nuevo censo que se pensaba realizar, el abreviado, pudiera incorporar la variable afrodescendiente. Al respecto su respuesta fue tajante: no había tiempo para eso. Lo que se buscaba con el Censo Abreviado era poder generar el marco de estadísticas mínimo necesario para la ejecución de las políticas públicas y por eso se restringiría la cantidad de preguntas. $Y$ pensar en ese escenario en incorporar una pregunta afrodescendiente, era imposible. Argumentó que ella venía recién llegando al cargo y que con el tiempo se podrían hacer las evaluaciones pertinentes para tratar el asunto. Si bien se le planteó la urgencia y la oportunidad que la nueva situación entregaba, se mantuvo en su posición.

Con posterioridad a esto, el 27 de febrero de 2015, las mismas organizaciones afrodescendientes presentaron sus demandas al poder ejecutivo, siendo nuevamente tajante la respuesta de la autoridad. Habiendo enviado una consulta a las autoridades, específicamente a la misma Presidenta de la Repú- blica, la respuesta recibida informaba que el gobierno estaba trabajando en una política de migrantes y que sin duda sus demandas serían entendidas en ese contexto. En lo específico la nota señalaba:

Que, primeramente, como Gobierno agradecemos el envío de vuestra carta, en este sentido, queremos señalar que con fecha 26 de enero de 2015 , se constituyó el Consejo Técnico de Política Migratoria (CTPM), instancia que asesorará el cumplimiento de la Política Nacional Migratoria y los acuerdos del Consejo de Política Migratoria, el cual fue creado por S.E. Presidenta de la República, Sra. Michelle Bachelet con fecha 11 de junio del año 2014, mediante Decreto N. 1393... Que, conforme a lo anterior esperamos que el Consejo Asesor Técnico de Política Migratoria avance a paso firme respecto de un correcto análisis en relación a la población afrodescendiente que habita actualmente en nuestro país, así como también, de la proposición de modificaciones a la normativa vigente que considere la actual realidad social y económica de Chile, en un contexto de globalización, pluriculturalidad, participación ciudadana y respeto irrestricto a los derechos humanos y las distintas convenciones sobre materias migrantes que ha suscrito el país (Ministerio de Desarrollo Social, 2015).

Si bien la carta enviada por las organizaciones planteaba claramente la demanda histórica y territorial de la gente de Azapa y de Arica, la respuesta del Ejecutivo encuadraba inexplicablemente la demanda afro en la condición de migrantes, no obstante, los demandantes llevaran más de 400 años viviendo en la región. Se reafirma así desde el poder ejecutivo, un argumento que repetía las negaciones anteriores: en Chile no hay negros, y solo es posible considerar a ese tipo de población producto de las migraciones de los últimos años en que han arribado a Chile colombianos, ecuatorianos, dominicanos, cubanos y haitianos, muchos de ellos afrodescendientes. De esta manera, nuevamente se negaba la existencia de los afros y se 
reafirmaba lo que se venía planteando desde los tiempos de la Guerra del Pacífico: los negros no son chilenos. O son peruanos, o de cualquier otro país, pero no pueden ser chilenos, ya que en Chile no hay negros.

En la primera mitad de 2015 , se fue avanzando sustantivamente en el reconocimiento afro por las mismas organizaciones y en el trabajo con distintas dependencias estatales, lo que ha sido visto como una política ambivalente y muchas veces contradictoria al interior del Estado, actitud por lo demás muy presente cuando se trata de los pueblos indígenas. Mientras en el ámbito nacional y en cuestiones tan importantes como el Censo o el Reconocimiento Legal, los avances han sido mínimos, en otros temas se ha progresado, sobre todo en el ámbito regional. Producto del trabajo que se realizó con la Municipalidad y el Gobierno Regional para la ENCAFRO, se propuso la creación de una Oficina Afrodescendiente que comenzó a trabajar al alero de la oficina indígena de la Comuna. A fines de 2013 se comenzó también a trabajar en la caracterización etnoterritorial de los afrodescendientes de Arica. En el año 2014 los afro fueron convidados a participar por primera vez en una consulta a nivel nacional, y al amparo del Convenio 169 de la OIT, para la creación del Ministerio de las Culturas. En el 2015 fueron incorporados a las políticas de fomento productivo, específicas para afrodescendientes, e incluso antes, el 2011, habían sido nombrados como Tesoros Humanos Vivos de Chile, por el Consejo Nacional de la Cultura y las Artes, el cual había también financiado sus actividades de bailes y de música desde el año 2003, mientras que la Secretaría de Turismo desarrollaba el Proyecto Ruta del Esclavo. En el año 2015 se realizó, además, un Informe en Derecho Acerca la
Situación Legal de los Afrodescendientes, a cargo de Nancy Yáñez (2015) y se comenzó a trabajar los primeros borradores de la nueva demanda de reconocimiento que se presentaría al Estado. En ese marco, se empezó a perfilar la idea de que el reconocimiento de lo afro se podría amparar en las demandas de reconocimiento indígena y que el Convenio 169 de la OIT, fuera ampliado a los afro en su calidad de pueblos tribales anteriores al estado nación. Esta situación no ha sido extraña en las Américas en donde en una gran cantidad de países, el reconocimiento de lo afrodescendientes ha sido posterior al indígena y se han utilizado los mismos marcos normativos, legales, jurídicos e institucionales para avanzar en ello (Wade, 2005).

En agosto de 2015, casi un año y medio después, se le solicitó una audiencia a la Sra. Ximena Clark, Directora Nacional del INE, en la que participaron Cristián Báez, por las organizaciones afrodescendientes; Fabiana del Popolo, por la CELADE², División de Población; Nancy Yáñez, abogada del Observatorio Ciudadano, experta en derecho indígena; y Luis Campos, Antropólogo, asesor de las organizaciones. En dicha reunión se le volvió a solicitar la inclusión de la pregunta distintiva y la respuesta fue la misma: no había tiempo para desarrollar y testear una nueva pregunta. Si bien faltaba cerca de un año y medio para la realización del Censo Abreviado 2017, todo el trabajo ya se estaba llevando a cabo y no era posible incorporar una nueva pregunta. Entre todos los argumentos que se levantaron ese día, el más sorprendente fue el que utilizó para encuadrar la demanda por la pregunta en el censo, en el marco de otras solicitudes que habían presentado distintos sectores de la sociedad. Se dijo que los discapacitados, los vendedores calleje- 
ros y los microempresarios se habían acercado al INE con la misma solicitud y que la respuesta también había sido negativa. Para ella era inconcebible que cualquier grupo, cualquier minoría, quisiera imponer sus demandas de ser contados, ya que así el censo se hacía inviable. Ante dicha respuesta, se le propuso que no era necesario crear una nueva pregunta, lo que facilitaba bastante el proceso y que bastaba con añadir una nueva categoría a la misma pregunta de identificación indígena. Situación que ya había ocurrido con anterioridad puesto que en el año 2006 se había reconocido legalmente al pueblo Diaguita, obligándose a que dicho pueblo apareciera como alternativa en el fallido Censo 2012. Por último, señaló que para ella los Afro sí estarían incluidos en el Censo Abreviado 2017 ya que existía en la pregunta indígena la categoría Otros, y que si verdaderamente se sentían negros, podían declararse como tales aprovechando esa categoría. Esto fue refirmado con posterioridad en carta enviada por la misma Directora Nacional en respuesta a los requerimientos de los afrodescendientes (INE, 2015):

El proceso de definición de los temas que serán incluidos en el cuestionario censal ha finalizado, y están básicamente determinados por los objetivos declarados para el Censo 2017, por lo que no es posible incluir una pregunta sobre pertenencia a la categoría "Afrodescendiente/Negro" en el Censo Abreviado 2017...Sin perjuicio de lo anterior es importante dejar en claro que aunque no se incorpore la categoría "Afrodescendiente/Negro" en el Censo Abreviado 2017, si existe el campo "otro (especifique)" en la pregunta de pertenencia a un pueblo indígena 'donde tanto los afrodescendiente/negro $u$ otros pueblos originarios $o$ tribales pueden autoidentificarse en este sentido...Si bien durante el año 2013 se realizó el levantamiento de 1aㅡ encuesta ENCAFRO en la Región de Arica y Parinacota, ello no implica atribuir una categoría jurídica $u$ oficializar a la población que se identificó como afrodescendiente. (p.1)

Lo que siguió fueron varias acciones desple- gadas por los afrodescendientes que comenzaron con un recurso de protección para detener el Censo, argumentando la abierta discriminación y exclusión, el que fue desestimado, primero por la Corte de Apelaciones y en segunda instancia por la Corte Suprema, argumentándose que ningún derecho garantizado por la Constitución había sido vulnerado, ya que los Afrodescendientes no han sido reconocidos legalmente en Chile. Es decir, una nueva negación, esta vez proveniente de la más alta magistratura que encierra la demanda en una paradoja de la que es difícil salir: la demanda de reconocimiento no puede ser aceptada ya que no han sido reconocidos. De esta manera, el 19 de abril de 2017 el Censo Abreviado se implementó sin la pregunta acerca de los afros y hasta la fecha no hay antecedentes de que el INE esté trabajando para abordar la situación seriamente para el censo de 2022. Es más, producto del fracaso en la justicia chilena, el 13 de septiembre de 2016, las organizaciones afrodescendientes de Arica interpusieron una denuncia ante el Sistema Interamericano de Protección de Derechos Humanos, caso que todavía está abierto y que busca reafirmar la exigibilidad del derecho a ser contados que tienen los afro chilenos y que en un futuro próximo podría obligar al Estado chileno a llevar a cabo todo lo necesario para que las políticas públicas incorporen la variable afro y también a reparar las consecuencias de la omisión.

Una segunda acción que han desarrollado los afrodescendientes, fue el asumir lo que entonces se entendió como una provocación de la directora del INE, cuando señaló que los afros estaban contemplados en el censo en la categoría "Otros". De esta manera durante todo el año 2016 en Arica y también a nivel nacional, se levantó una campaña a través de los medios 
virtuales y con trabajo puerta a puerta, con el objetivo de que se respondiera a la pregunta sobre los pueblos indígenas como Otro, y que señalaran específicamente la pertenencia afrodescendiente. Uno de los principales slogans utilizados en la campaña hizo referencia al lema del Censo Abreviado 2017: "En el Censo Todos Contamos", a lo que se le agregó “...Menos los Negros...". Hubo entrevistas en medios de difusión masiva y se difundió un video en donde explicaban la situación de los afro y la exclusión que habían sufrido, llamando a todos los interesados a declarase como afrodescendientes.

El día 21 de abril el Observatorio Ciudadano emitió una opinión pública en que criticaba la exclusión en el Censo Abreviado 2017, argumentando que:

La necesidad de contar con información oficial y desagregada, que incorpore la dimensión étnica basada en la autodefinición, con el objetivo de implementar políticas públicas focalizadas y pertinentes a los miembros de las comunidades afrodescendientes en Chile, ha sido observada y recomendada por múltiples organismos internacionales, tales como el Comité para la Eliminación de la Discriminación Racial (CERD, por sus siglas en inglés), órgano de control de la Convención Internacional sobre la Eliminación de todas las Formas de Discriminación Racial. Asimismo, ha sido recomendado por la Comisión Interamericana de Derechos Humanos a los Estados de la región, a partir del acervo de decisiones y jurisprudencia desarrollada en el Sistema Interamericano de Derechos Humanos.... (p.1)

Hasta la fecha las conversaciones con el INE están detenidas y las organizaciones estiman que difícilmente la Directora Nacional de la institución llegará a algún acuerdo, ya que se sintió presionada al tener que enfrentar un proceso judicial. Las conversaciones con el poder ejecutivo tampoco han progresado. Lo que sí ha avanzado es la iniciativa para el reconocimiento afrodescendiente. Con el apoyo de diputados de la región de Arica se ha presentado una moción de reconocimiento al parlamento que ya fue discutida por la Comisión de Derechos Humanos, que es la primera instancia en donde los diputados ven el caso. Se trabajó con la comparecencia de especialistas y de las organizaciones, y se espera que a la brevedad pueda ser llevada a discusión en las respectivas cámaras, si bien no está claro si el gobierno dará apoyo a la tramitación legislativa. En realidad, las urgencias parlamentarias son otras, y el Ejecutivo no ha demostrado interés, por lo que es posible que tampoco se alcance a ver durante este gobierno.

En suma, lo que ha quedado de toda esta historia son las tres iniciativas que actualmente están llevando a cabo los afro: Denuncia ante la Corte Interamericana, Campaña para llenar de contenido al Otro en el Censo y la Moción de Reconocimiento en el parlamento. Se espera que en conjunto esas iniciativas ayuden a que se avance, tanto en el reconocimiento, como en la inclusión de la pregunta diferencial en el próximo censo. Las respuestas de las autoridades han evidenciado cómo en Chile siguen operando diferentes mecanismos de exclusión que se sustentan en una lógica discriminatoria que sin duda está en concordancia con las definiciones que Chile ha realizado históricamente para tratar con la diferencia cultural. Cada acción de exclusión tiene en si un presupuesto que refleja el trasfondo cultural que niega la diferencia y las fallas de reconocimiento que operan actualmente en la relación entre el Estado, la sociedad civil y los afrodescendientes. Presento aquí un detalle de estos mecanismos manifestados en los argumentos que han debido enfrentar en más de 15 años de movilizaciones por 
el reconocimiento afrodescendiente en Chile y que expresan mecanismos de defensa que siguiendo a Lipschutz (1944) podríamos identificar como hipocresía racial.

1. Los negros no existen. La pregunta que está detrás de esta afirmación apunta a una interrogante basal que sustenta todo el andamiaje de exclusiones: ¿para qué contar a los negros en Chile si estos no existen? Como se ha visto es una negación que se reproduce desde los primeros años de la república y está marcada por el carácter eurocéntrico, racista y pigmentocrático que asume el estado nación chileno desde tiempos de su conformación.

2. Es un fenómeno regional. En segundo lugar, reconociendo la existencia de las demandas y la presencia de afros en diferentes reuniones, si es que efectivamente existen, es un fenómeno específico que sucede en Arica (de donde provenía la demanda) y por lo tanto no vale la pena hacer el esfuerzo de incorporar una pregunta a nivel nacional. La demanda es estrictamente regional, localizada, microscópica y afecta en definitiva a pocas personas. De esta manera cualquier política pública que se pueda implementar será de bajo impacto, no justificándose la inversión de cuantiosos recursos para el beneficio de tan pocas personas.

3. Es muy complicado o no se tiene la experiencia suficiente. En tercer lugar, aun cuando se dejaran de lado las razones anteriormente esgrimidas, la operación de contar a los negros es muy complicada, (nunca se ha realizado antes), y no se tiene la experiencia suficiente para enfrentar ese proceso. Además, lo sucedido con la pregunta indígena en los censos anteriores, reafirma la poca competencia del servicio público para realizar la tarea.

4. No hay tiempo. En cuarto lugar, aun cuando se cumplieran todas las exigencias anteriores, como ya era 2008 (y luego 2014 para el Censo Abreviado), no daba tiempo para incorporar la pregunta en el censo. Esta afirmación fue expresada más de tres años antes del Censo 2017 por la Directora Nacional del INE. Tanto para el punto anterior como para la falta de tiempo, se le ofreció el apoyo del CELADE, organismo que ha realizado varias recomendaciones con respecto a la obligatoriedad de la incorporación de una pregunta que permita dar cuenta de los afrodescendientes en América Latina. Al respecto, solo basta recordar el documento final presentado por CEPAL (2013), conocido como Consenso de Montevideo, en que se recomienda:

Considerar las dinámicas demográficas y socioculturales particulares de las poblaciones afrodescendientes en el diseño y la aplicación de las políticas públicas garantizando su plena participación, y el desarrollo de estadísticas desagregadas...y al mismo tiempo... Generar conocimiento e información confiable y oportuna con perspectiva de género y desagregado por sexo, edad y condición socioeconómica, entre otras variables, sobre las poblaciones afrodescendientes, a través de procesos participativos, atendiendo los requerimientos y las recomendaciones internacionales relativas al asunto. (p.3)

5. Alta demanda de diferentes sectores por ser contados. En este caso no se diferencia la demanda afrodescendiente de las demandas de otros sectores sociales, como los microempresarios, las personas con habilidades especiales, la diversidad de género y otras actividades productivas. No se entiende la especi- 
ficidad de lo racial y lo étnico que involucra la demanda afrodescendiente. Este argumento tiende a insistir que las especificidades sociales y culturales, las identidades preexistentes a los estados, como las indígenas y las afrodescendientes, están en el mismo nivel que otras diversidades surgidas como producto de la consolidación de los estados naciones, en una perspectiva de multiculturalismo generalizado (Kymlicka, 1996).

6. Los afrochilenos como migrantes. En el año 2015 se respondió a las demandas afrodescendientes argumentando que sus demandas serían consideradas en la nueva ley de migrantes que se estaba preparando en el país (que a la fecha no ha sido aprobada). Nuevamente con este argumento se insistió en la no pertenencia de los afros al país. Se repite así la clasificación inicial, impuesta luego de la Guerra del Pacífico y que establece que los afrodescendientes no son chilenos. Lo anterior no implica que la ley de migración no sea necesaria, sobre todo cuando se está pensando en restringir la llegada de más afrodescendientes a Chile con la implementación de un visado espacial para haitianos y dominicanos.

7. En el censo están contemplados como Otros. Por último, ya en el 2016 y en el marco por las discusiones en torno al Censo Abreviado 2017, se argumentó que en lo que respecta a la pregunta indígena, ya existía la categoría Otros y, por lo tanto, los afrodescendientes si es que así lo querían, podían auto identificarse como Otros y luego decir que ese "otro" era afrodescendiente. Este argumento entra en la lógica de los eufemismos tan característicos de la historia de Chile, siendo el más conocido aquel que denomina a la invasión de la Araucanía como Campaña de Pacificación. Los eufemismos también se han ocupado en otros países como la misma Campaña del Desierto en Argentina, o el avance hacia los Sertoes en el Brasil, paradójicamente espacios considerados vacíos, pero ocupados por indígenas y por quilombolas. Este último argumento desvela la forma en que se está manifestando el racismo estructural en Chile siendo uno más de los mecanismos de discriminación y de exclusión creados por el discurso racista de las elites gobernantes y nuevamente un claro ejemplo de la hipocresía racial.

\section{Reflexiones finales}

El caso de la exclusión en el Censo Abreviado 2017 y más de diez años luchando por un reconocimiento legal, han dejado en evidencia muchos de los prejuicios y estigmas con que se ve a la población afro en Chile. Desde sus inicios como República, el país se definió como una nación mestiza, indígena española, sin población negra. Incluso los indígenas fueron lentamente excluidos de la idea de nación como lo han demostrado muchos trabajos (Pinto, 2000; Bengoa, 2000). Si bien la presencia africana en tiempos coloniales no llegó a los volúmenes de otros países con extensos sistemas de plantación, hay evidencias históricas de procesos judiciales, se ha estudiado su influencia en la música y el baile, incluso en el baile nacional y la participación de negros en las batallas por la Independencia y en la misma Guerra del Pacífico. Todo esto pone en evidencia el hecho de que la no existencia de negros en Chile tiene más que ver con un fenómeno discursivo que, amparado en una matriz eurocéntrica, pasa a concebir un país 
en donde negros e indios no tienen cabida. Tal como lo planteó Quijano (2003) en Latinoamérica se estableció un sistema de clasificaciones basado en la raza, siendo a partir de entonces marcados como negativas aquellas personas que no representaban el ideal caucásico europeo. Se establecen así las bases de una sociedad pigmentocrática, en la cual no solo no es posible acceder a determinados puestos, sino que inhibe también la posibilidad de llegar a ser considerados connacionales, definiendo una pigmentocracia de pertenencia nacional. Y como bien dice Stavenhagen (1998), lo anterior permitió el establecimiento de un sistema de control económico y de administración basado en el color y la cultura. Estas condiciones generadas en tiempos coloniales, son las que se van a repetir en las nacientes repúblicas y se van a acentuar con la consolidación de los estados-naciones y con las guerras por territorios de mediados y fines del S. XIX. En este contexto, las elites chilenas van a consolidar entre 1870 y 1900 los límites actuales, reafirmando los idearios eurocéntricos expandiéndose hacia el norte con la Guerra del Pacífico, afectando a indígenas y afrodescendientes; con la Pacificación de la Araucanía, en contra de los mapuche; y con la anexión de la Isla de Pascua (1889), que impacta sobre el pueblo Rapa Nui. En estos tres casos se argumentará sobre la debilidad, el desorden y la barbarie y con la necesidad de civilizar estos territorios, lo que implicaba volverlos culturalmente europeos y racialmente blancos.

En el caso específico de la Guerra del Pacífico, permitió a Chile anexarse las provincias del norte, en donde habitaba una gran cantidad de afrodescendientes, al punto que se decía que Arica se asemejaba un poco a África (Urzúa, 1964). En ese mismo tiempo se levantó la idea de que los negros no eran chilenos, sino peruanos, lo que fue utilizado en las campañas de chilenización y que implicó que los negros fueran perseguidos y expulsados del país, ya que se necesitaba que esas provincias fueran cultural y racialmente chilenas. Se impone así una lógica nacionalista pigmentocrática que es determinante para la construcción de la nación en un contexto de creciente diferenciación de Chile con respecto a los países vecinos. El ejemplo de la propaganda del tiempo de la Guerra del Pacífico en la cual los peruanos son negros y los bolivianos indígenas, refleja también a un chileno mestizo blanco, de marcada raigambre europea (Díaz, Galdames \& Ruz, 2013). Ese prejuicio, más bien esa disposición, se ha mantenido hasta la actualidad y la insólita respuesta de las autoridades asociando la demanda afro al proceso migratorio es un claro ejemplo de eso. A inicios del S. XXI los negros siguen siendo los extranjeros, siendo más fácil reconocerlos como "otros", y no siendo parte de la misma nación, como connacionales.

Sin duda el tema de los migrantes será primordial a la hora de profundizar en el reconocimiento y en la visibilidad de los afrodescendientes en Chile. Al respecto el movimiento afrochileno comenzó con una demanda de reconocimiento interna, pero en pocos años se han vinculado con la situación de los migrantes, pasando a entenderse más allá de la especificidad de la situación en la Región de Arica o del resto de Chile (Walker, 2012). La relación con los migrantes afro los vincula con un movimiento mayor y les ha dado más herramientas para enfrentar los procesos de exclusión que han vivido. En los últimos años Chile está cambiando radicalmente y se hacen cada vez más necesarios los estudios y políticas públicas específicas, no sólo para migrantes, sino 
para migrantes afrodescendientes, los que están llegando a un país con importantes déficits en dicho reconocimiento. También llegan a un país que no está acostumbrado a enfrentarse de manera simétrica con los afro, siempre lleno de racismo, estigmas y discriminación, como se ha visto, incluyendo las opiniones y decisiones de las mismas autoridades que refuerzan la idea de una sociedad pigmentocrática. El esfuerzo que están realizando los afrochilenos sin duda ayudará al nuevo marco cultural y legal que debe enfrentar Chile, lo que no significa que no se deba reconocer la especificidad de la demanda de comunidades históricas y ancestrales y la necesidad de ser reconocidos legalmente y contados en el Censo de 2022. Este reconocimiento debe ser explícito y avanzar hacia la visibilidad de lo negro-afrodescendiente en el país y no puede seguir escudándose en categorías eufemís- ticas, marcadas de hipocresía racial, tan utilizadas en Chile, como incluirlos dentro de los migrantes, o considerar que la categoría Otro en el Censo 2017 contempla a los afro. A pesar de la campaña que se realizó antes del Censo Abreviado 2017, la categoría Otro sigue siendo simplemente el "otro", el distinto, el que no se corresponde con lo que yo soy, siendo una evidente falta de reconocimiento que se sigue viviendo en Chile.

En definitiva, la exclusión de los afrodescendientes de los dos últimos censos en el país, la falta de reconocimiento a través de una disposición legal específica, el circunscribir su demanda como migrantes y el pensarlos como Otros, han abierto las puertas que evidencian el racismo nacional de una sociedad pigmentocrática en donde los negros no tienen cabida. 


\section{Notas}

${ }^{1}$ Comisión Económica para América Latina y el Caribe.

${ }^{2}$ Centro Latinoamericano y caribeño de demografía.

Institución que forma parte del trabajo de la CEPAL.

\section{Referencias bibliográficas}

Alarcón, J., Araya, I. \& Chávez, N. (2017). Identidad negra en tiempos de globalización. Memorias de abuelos y abuelas afrodescendientes de Arica y el Valle de Azapa. Santiago: Consejo Nacional de la Cultura.

Báez, C. (2010). Lumbanga. Memorias Orales de la Cultura Afrochilena. Santiago: Fondo Cultura: Libro y Lectura.

Bengoa, J. (2000). La emergencia indígena en América Latina. Santiago: Fondo de Cultura Económica.

Briones, C. (1998). La alteridad del cuarto mundo. Una deconstrucción antropológica de la diferencia. Buenos Aires: Ediciones El Sol.

(2002). Mestizaje y blanqueamiento como coordenadas de aboriginalidad y nación en Argentina. Revista Runa, 23 (1), 61-88.

Briones, V. (2004). Arica Colonial: libertos y esclavos negros entre el Lumbanga y las Maytas. Chungará, 36(Suppl), 813-816.

Campos, L. (1999). Negros y morenos. La población Afromexicana de la Costa Chica de Oaxaca. En Bartolomé, M.A. \& Barabas, A (Coord.) Configuraciones Étnicas en Oaxaca. -(pp.145-182). México: INI-INAH.

(2014). El reconocimiento de nuevas identidades: cómo enfrentar la etnogénesis desde la Academia. En Trinchero, H, Valverde, S. \& Campos, L. (Coord). Pueblos Indígenas, Estados nacionales y fronteras. Tensiones y paradojas de los procesos de transición contemporáneos en América Latina. Buenos Aires: Clacso - UBA - UAHC.

(2016). El patrimonio y las demandas de reconocimiento cultural. En Alvarado, M. (Et.al). Patrimonio y pueblos indígenas. Reflexiones desde una perspectiva interdisciplinaria e intercultural (pp.67-74). Santiago: ClIR-Pehuén.

Campos, L. \& Espinosa, M. (2017). Informe final Proyecto Recolección y clasificación de datos etnoterritoriales afrodescendientes de la Región de Arica y Parinacota. Mimeografiado. Santiago: Municipalidad de Arica - Oficina Afrodescendiente - UAHC

CEPAL. (2013). Consenso de Montevideo sobre población y desarrollo. Primera reunión de la Conferencia Regional sobre Población y Desarrollo de América Latina y el Caribe. Montevideo: CEPAL.

Cid, G. (2012). La nación bajo examen: La historiografía sobre el nacionalismo y la identidad nacional en el siglo XIX chileno. Polis, 11(32), 329-350. https://dx.doi.org/10.4067/S071865682012000200016

Del Canto, G. (2003) Oro Negro. Una aproximación a la presencia de comunidades afrodescendientes en la ciudad de Arica y el Valle de Azapa. Santiago: Semejanza.

Díaz, A., Galdames, L. \& Ruz, R. (2013). Y llegaron con cadenas: las poblaciones afrodescendientes en la historia de Arica y Tarapacá (siglos XVII-XIX). Arica: Universidad de Tarapacá.

Duconge, G. \& Guizardi, M. (2014a). Diásporas, etnicidad y etnogénesis: de las reflexiones teóricas a los estudios de caso sobre las comunidades afro-descendientes en América Latina. Papeles de Trabajo (28), 95-119.

(2014b). Afroariqueños: configuración de un proceso histórico de presencia. Revista Estudios Atacameños (49), 129-151.

Espinosa, M. (2013). Reconstrucción identitaria de los afrochilenos de Arica y el Valle de Azapa. Tesis inédita para optar al título de Antropólogo y al grado de Licenciado en Antropología Social, UAHC, Santiago.

Geler, L. (2010). Andares negros, caminos blancos. Afroporteños, Estado y Nación en Argentina a fines del siglo XIX. Rosario: Protohistoria.

Gilroy, P. (2014). Atlántico negro. Madrid: Akal.

González, S. (2004). El Dios Cautivo: Las ligas patrióticas en la chilenización compulsiva de Tarapacá (1910-1922). Santiago: Lom.

Guzmán, F. \& Geler, L. (2013). Cartografías afrolatinoamericanas. Perspectivas mestizas para análisis transfronterizos. Buenos Aires: Biblios.

INE. (2014). $1^{a}$ Encuesta de caracterización de la población afrodescendiente. Región de Arica y Parinacota. Arica: INE.

(2015). Carta Respuesta de la Directora Nacional Ximena Clark a la respuesta a la presentación remitida por el Jefe de Gabinete de la Subsecretaria de Economía y Empresas De Menor Tamaño, respecto del documento enviado por el "Movimiento Político, Socialy Cultural Afrodescendiente en Chile", a la Presidencia de República. ORD. N. 2401. 16 de diciembre. Santiago: INE.

Klein, H. (1999). The Atlantic slave trade. New York: Cambridge University.

Kymlicka, W. (1996). Ciudadanía multicultural. Barcelona: Paidós Ibérica.

Lipschutz, A. (1963). El problema racial en la conquista de América y el mestizaje. Santiago: Austral.

(1944). Indoamericanismo y el Problema Racial en las Américas. Santiago: Nascimiento.

Ministerio de Desarrollo Social. (2015). Carta No 10. Carta enviada por el Coordinador Nacional de Consulta y Participación Indígena a 
Cristián Báez como respuesta a carta enviada a Presidenta de la República Sr. Michelle Bachelet Jeria. 23 de marzo. Santiago: MIDESO.

Observatorio Ciudadano. (2017). El Censo y la exclusión de los afrodescendientes. Declaración Pública, http://www.mapuexpress. org/?p=17426, 21 de abril de 2017.

Oliveira, A. (2002). Fragmentos da etnografía de uma rebelião do objeto: indigenismo e antropología em tempos de autonomía indígena. Revista Anuário Antropológico (1), pp. 109-130.

(1998). Invisibilidade imposta e estratégia de Invisibilização entre negros e índios: uma comparação. En Caroso, C. (Et.al). Brasil:um país de negros? (pp. 165-174). Rio de Janeiro: Palas.

Pinto, J. (2000). De la inclusión a la exclusión: la formación del estado, la nación y el pueblo Mapuche. Santiago: USACH.

Quijano, A. (2003). Colonialidad del poder, eurocentrismo y América Latina. En Lander, E. (Comp.), La Colonialidad del saber: eurocentrismo y ciencias sociales. Buenos Aires: Clacso.

Restrepo, E. (2013). Etnización de la negridad: la invención de las comunidades negras como grupo étnico en Colombia. Popayán: Universidad del Cauca.

Ruz, R., Galdames, L. \& Díaz, A. (2015). Junta de Adelanto de Arica (1858-1976). Experiencia, documentos e historia regional. Arica: Universidad de Tarapacá.

Salgado, M. (2013). Afrochilenos: una historia oculta. Arica: Ediciones Krom.

Stavenhagen, R. (1998). El sistema internacional de los derechos indígenas. En Bartolomé, M.A. \& Barabas, A. Autonomías Étnicas y Estados Nacionales. México: Conaculta-INAH.

Telles, E. (2014). Pigmentocracies: Ethnicity, Race and Color in Latin America. Chapel Hill: University of North Carolina.

Telles, E. \& Steele, L. (2012). Pigmentocracia en las América: ¿cómo se relaciona el logro educativo con el color de piel? Perspectivas desde el barómetro de las Américas, Vandelbilt University.

Thomas, H. (1998). The slave trade. The history if the Atlantic slave trade 1440 - 1870. Oxford: Macmillan.

Urzúa, L. (1964) Arica, puerta nueva. Santiago: Andrés Bello.

Valle, M. (2014) Inmigrantes afrodescendientes en Santiago de Chile: procesos de estigmatización y resistencia retórica. Revista Trabajo Social (87), 3-19.

Van Dijk, T. (2003). Racismo y discurso de las elites. Barcelona: Fondo de Cultura Económica.

Wade, P. (2005). La política cultural de la negritude en Latinoamérica y el Caribe. En Guaraguao, Revista de Cultura Latinoamericana, 9 (20), 8-38. (2000). Raza y etnicidad en Latinoamérica. Quito: Abya Yala.

Waldman, G. (2004). Chile: indígenas y mestizos negados. Política y cultura (21), 97-110. Recuperado en 09 de agosto de 2017, de http://www.scielo.org.mx/scielo.php?script=sci_arttext\&pid=S0188$77422004000100007 \&$ Ing=es\&tlng=es.

Walker, S. (2012). Conocimiento desde adentro. Los afrosudamericanos hablan de sus pueblos y sus historias. Popayán: Universidad del Cauca.

Wormald, A. (1972). Historias olvidadas del Norte Grande. Arica: Universidad del Norte. Ráfaga. (1969). El mestizo en el departamento de Arica. Santiago: (1968). Frontera norte. Santiago: Orbe.

Yáñez, N. (2015). Informe en derecho de la situación afrodescendiente en Chile desde la perspectiva de los derechos humanos. Mimeografíado. Santiago: Proyecto Fondecyt 1150876. 